\title{
Optimizing the selection process of document-management systems
}

\author{
Jan Henrik Dornberg ${ }^{1}$, Laura Lohmüller ${ }^{1}$ \\ ${ }^{1}$ FIR e. V. an der RWTH Aachen \\ Institute for Industrial Management at RWTH Aachen University
}

\begin{abstract}
Due to the rising amount of digital information nowadays, many small and medium-sized enterprises (SMEs) begin to increasingly recognize the value of document management systems (DMS). There has already been done an extensive amount of research in the field of DMS, which however has been focusing almost exclusively on the technical aspects of DMS and the aspect of usability was rarely included. This is because, so far, there exist no objective criteria for measuring usability. This paper elaborates on how to make usability aspects measurable in order for them to be integrated into the selection process of DMS.
\end{abstract}

Keywords: Usability, Document Management, Human-computer-interaction, Usability engineering

\section{Introduction}

Nowadays document-management systems (DMS) become increasingly important for small and medium-sized enterprises (SMEs). These systems help the user with the automation of most of the processes connected with classification, editing, saving, and distribution of documents. They transform electronically generated and unstructured information into manageable and easy to retrieve documents [1]. Furthermore, achievements stemming from successful integration of
DMS include long-term cost savings, improved processes and higher employee motivation and customer satisfaction [2].

The research, which has been conducted so far, has been focusing almost exclusively on the technical aspects of DMS and they rarely included the aspect of usability [3]. This is due to the fact that it is difficult to formulate requirements for usability, which can then be measured objectively. "[...] there are few clear guidelines about how various definitions of usability factors, rules, and criteria are related (if at all) and how to select or measure specific aspects of usability [...]" [4]. Furthermore, many software developers are intimidated by the complexity of usability engineering techniques and consider them too time consuming and expensive [5].

Nevertheless, usability is a characteristic that is getting more and more important $[4,6,7]$, especially in softwareprograms like DMS. However, whether a program's usability is high or low can only be recognized when the program is already implemented and ready for use. For most SMEs taking usability into account at only this point of time is too late.

In this paper a new way of evaluating DMS will be introduced, in which the aspect of usability is included in the beginning of the selection process. This approach is being developed in context of the research project "uSelect DMS" (supported by the German Federal Ministry of Economics and Technology, Grant 
01MU12020). The aim of this project is to make the usability of DMS visible and measurable and to integrate the aspect of usability into the DMS selection process. In order to reach this goal, several usability criteria are identified and evaluated. Afterwards ways of measuring those criteria will be developed and, in a next step, the results will be integrated into the selection process of DMS. The use of those usability criteria will create the possibility to exclude DMS with low usability already in the beginning of the selection process.

\section{DMS Selection Process}

Since nowadays there are more than 100 providers for DMS, it gets extremely difficult to differentiate between them. Especially when looking at their technical functions, most of them are very similar to each other. With the help of different methods and concepts it is tried to identify the right fit between a DMS and an organization.

This process typically starts with an analysis of the organization with regard to their document- and information flows. In this phase the potential of implementing a DMS into the organization is examined. In order to do this, the firm's processes and document flows are analyzed and the costs and benefits of implementing a DMS are established.

When deciding in favor of a DMS, the typical selection process starts (Figure 1). This process is used to narrow down the potential DMS providers until the best fitting DMS for an organization is found.

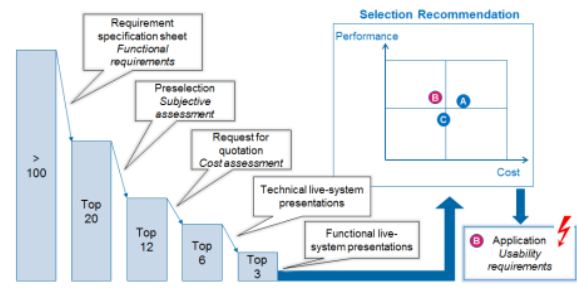

Fig. 1: Typical selection process

The typical selection process starts with doing a preselection of the DMS which might fit to the organization. In order to preselect between the different DMS, a requirement specification sheet is used to further specify and prioritize several characteristics which are important to the organization. With the help of a database one is then able to assess DMS which fit the requirements of the respective organization. Afterwards, the preselected DMS providers are contacted and asked to make an official proposal, which will then be examined on technical functions, price and reference. Finally, a few selected DMS providers will be invited to do a live-system presentation. In this presentation the organization will especially look at the functionality of the system, the needed preconditions, the recovery and the ability of integration. Based on those analyses, one DMS provider will be selected and the system will be implemented into the organization.

\section{Usability in DMS}

It can be seen from the description of the typical selection process, that usability aspects will be identified quite late during the live-system presentations. Before that it is, so far, not possible to integrate usability as a selection criterion, since it is not measurable. The goal of the project "uSelect DMS" is to make usability measurable and to then integrate the usability characteristics into the requirement specification sheet. When usability is in- 
tegrated into the requirement specification sheet, it is possible for organizations to specify which usability aspects are important for them and on this basis they can then already preselect some of the DMS providers which do provide those usability criteria.

Usability is defined by ISO 9241 part 11 [8] as the "extent to which a product can be used by specified users to achieve specified goals with effectiveness, efficiency and satisfaction in a specified context of use". That means that reliable measures of overall usability can only be obtained by assessing the effectiveness, efficiency, and satisfaction with which a user operates on a DMS. However, it is very difficult to assess those characteristics, since they also depend on the context in which the DMS is used. User characteristics might make differences in their ability to handle a product. A product which is easy to use by trained users might be difficult to handle by untrained users. Moreover "aspects of the working environment such as lighting, noise, or workstation design may also affect usability" [9].

Therefore, it can be seen that many factors influence the process of developing usability criteria for DMS. Figure 2 shows that the DMS, the user, the context of use and the requirement specification sheet are tightly connected and that the whole process of developing usability criteria should be centered around the user.

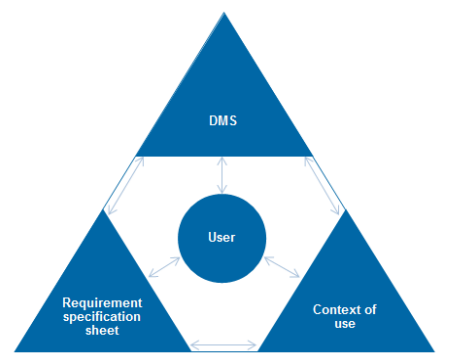

Fig. 2: Reference framework
In order to find perfectly fitting usability criteria for the requirement specification sheet it is mandatory to take a second and closer look at the other three categories.

Figure 3 shows the DMScharacteristics fanned out into another three subcategories. These include the type of client, area of operation and the depth of integration.

\begin{tabular}{|c|c|c|c|c|}
\hline \multicolumn{5}{|c|}{ DMS characteristics } \\
\hline $\begin{array}{l}\text { type of } \\
\text { client }\end{array}$ & mobil & full & smart & web \\
\hline $\begin{array}{l}\text { area of } \\
\text { operation }\end{array}$ & input & filing & output & $\begin{array}{c}\text { colla- } \\
\text { boration }\end{array}$ \\
\hline $\begin{array}{l}\text { depth of } \\
\text { integration }\end{array}$ & low & & & high \\
\hline
\end{tabular}

Fig. 3: DMS-characteristics

The description of the context of use should consist of the type of process, function, document, file as well as the place of use. (Figure 4)

\begin{tabular}{|c|c|c|c|c|c|c|c|}
\hline \multicolumn{8}{|c|}{ Context of use characteristics } \\
\hline $\begin{array}{l}\text { type of } \\
\text { process }\end{array}$ & \multicolumn{2}{|c|}{ key process } & \multicolumn{3}{|c|}{ support process } & \multicolumn{2}{|c|}{$\begin{array}{l}\text { managemen } \\
\text { process }\end{array}$} \\
\hline $\begin{array}{l}\text { type of } \\
\text { function }\end{array}$ & \multicolumn{2}{|c|}{ input } & \multicolumn{2}{|c|}{ filing } & output & \multicolumn{2}{|c|}{$\begin{array}{c}\text { collabo- } \\
\text { ration }\end{array}$} \\
\hline $\begin{array}{c}\text { type of } \\
\text { document }\end{array}$ & \multicolumn{4}{|c|}{ external document } & \multicolumn{3}{|c|}{ internal document } \\
\hline type of file & $\begin{array}{l}\frac{\overline{\frac{\omega}{0}}}{\overline{\frac{0}{2}}} \\
\frac{\bar{s}}{\omega}\end{array}$ & 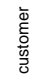 & 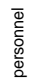 & $\begin{array}{l}\text { \& } \\
\text { ठ } \\
\text { 뭉 }\end{array}$ & $\begin{array}{l}\frac{\bar{d}}{0} \\
\frac{\stackrel{0}{0}}{2}\end{array}$ & 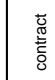 & 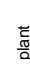 \\
\hline place of use & \multicolumn{4}{|c|}{ mobil } & \multicolumn{3}{|c|}{ stationary } \\
\hline
\end{tabular}

Fig. 4: Context of use-characteristics

When describing the User-characteristics (Figure 5) important aspects may include the IT-Knowledge, hierarchy level, qualification, primary area of work, education and handedness. Furthermore, it might be necessary to categorize different types of 
users, for example power-users versus occasional-user.

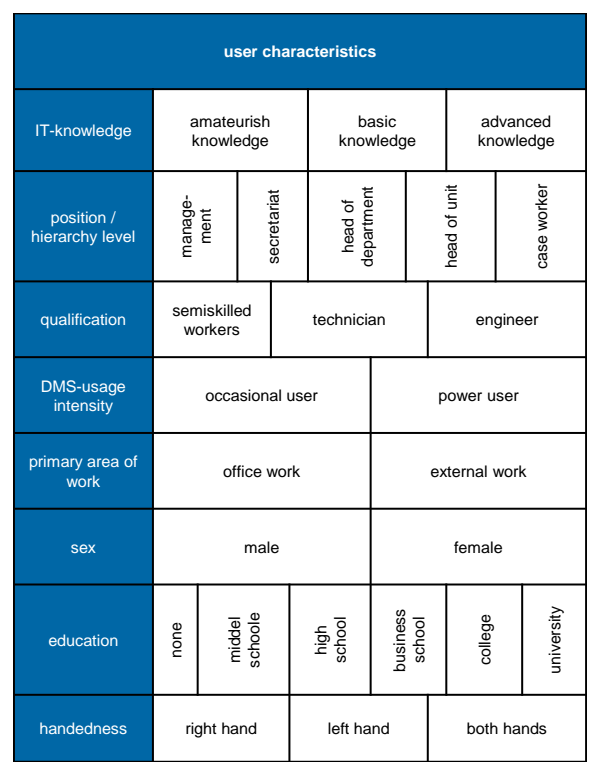

Fig. 5: User-characteristics

These Characteristics and requirements, which stem from the context of use of a DMS, need to be transformed into usability requirements, in order for them to be implemented into a requirement specification sheet. It is thereby essential that the features listed above have a minimum redundancy and are clearly defined. That's the only way to ensure that the DMS-user can make the best choice for himself. Finally, those resulting usability criteria need to be integrated into the system development and improvement of DMS.

This analysis will also be done in the project "uSelect DMS". In order to get to the information of the user context, a working group for the topic of software ergonomics will be established, in which users of the target groups as well as providers of DMS can participate. Questionnaires will be given to the participants of this working group, and with the help of these answers, different user groups will be established. Following this, workshops and expert interviews will be conducted in order to derive certain requirements of usability in DMS. Additionally, the weak spots of existing DMS will be analyzed, which will then also contribute to the construction of usability requirements. It is however, equally important to identify the advantages of DMS and to then eliminate as much of the weaknesses of the system as possible, without negatively influencing the advantages [10]. The weak spots of DMS include, for example a time consuming process of converting paper documents into digital documents. Moreover, implementing a DMS means a high workload for indexing the documents, which also leads to a high amount of work in front of the computer screen [11].

\section{Conclusion}

In summary it can be seen that usability gains more and more importance, especially in software programs like DMS. The technical aspects of DMS are of course still relevant and important. However, as long as the usability of a product is low, the technical aspects can be as good as possible, but the user will still be unsatisfied. Therefore, the "uSelect DMS" project tries to find ways to make usability measurable and to consider usability criteria in the selection process of DMS. When usability aspects can be integrated into the selection process, it will be much easier for organizations to find the best fitting DMS for their company. Furthermore, it will also help DMS providers to improve the usability of their products and to compare those products to the ones of other DMS providers.

\section{References}

[1] R. Dilnutt, "Enterprise Content Management: Supporting 
Knowledge Management Capabil-

ity," International Journal of

Knowledge, Culture and Change

Management, 2006, pp. 73-84, 2006.

[2] C. A. Stern, Potentialanalyse:

Einsatz eines Dokumenten

Management Systems (DMS) im

Vertrieb eines Großunternehmens, 1st ed. Hamburg: Diplomica Verlag $\mathrm{GmbH}, 2008$.

[3] M. Woywode and A. Mädche et al, Gebrauchstauglichkeit von

Anwendungssoftware als

Wettbewerbsfaktor für kleine und mittlere Unternehmen (KMU).

Available: http://www.usability-ingermany.de/ergebnis (2012, Dec. 04).

[4] A. Seffah, M. Donyaee, R. B. Kline, and H. K. Padda, "Usability measurement and metrics: A consolidated model," Software Quality Journal, 2006, pp. 159-178, 2006.

[5] J. Nielsen, "Using discount usability engineering to penetrate the intimidation barrier," in Cost-justifying usability, R. G. Bias and D. J. Mayhew, Eds, Boston: Academic Press, 1994, pp. 245-272.

[6] J. Bosch, J. van Grup, and E. Folmer, "Software architecture analysis of usability," in EHCI-DSVIS'04 Proceedings of the 2004 international conference on Engineering Human Computer Interaction and Interactive Systems, R. Bastide, P. Palanque, and J. Roth, Eds, Heidelberg: Springer-Verlag Berlin, 2005, pp. 38-58.

[7] M. Richter and M. Flückiger, Usability Engineering kompakt:

Benutzbare Software gezielt entwickeln, 1st ed. Heidelberg: Elsevier Spektrum Akad. Verl, 2007.

[8] 9241-11 Ergonomic requirements for office work with visual display terminals (VDTs) - Part 11 : guidance on usability, ISO/IEC 9241-11, 1998.

[9] N. Bevan and M. Macleod, "Usability measurement in context," Behaviour and Information Technology, vol. 13, no. 1-2, pp. 132-145, 1994.

[10] F. Sarodnick and H. Brau, Methoden der Usability Evaluation: Wissenschaftliche Grundlagen und praktische Anwendung, 1st ed. Bern: Huber, 2006.

[11] J. Dandl, "DokumentenManagement-Systeme: Eine Einführung," Mainz, 1999. 